\title{
INNOVATION APPROACH TO OBTAIN THE PACKED RED CELLS FROM THE SLAUGHTER ANIMAL BLOOD
}

\author{
Alexandr V. Izgarishev *, Konstantin V. Karchin, Natalia V. Izgarisheva
}

Kemerovo Institute of Food Science and Technology (University), Stroiteley blvd. 47, Kemerovo, 650056 Russian Federation

Received May 2, 2016;

Accepted in revised form June 10, 2016;

Published December 30, 2016

\begin{abstract}
This paper is aimed to develop stabilizers with the conserving effect that helps to prolong the expiry date with the blood stabilization up to the relevant processing, including the fractionation characteristic selection. Theoretical and experimental studies are performed to comply with the tasks at hand at the "Bionanotechnology" Chair of the Kemerovo Institute of Food Science and Technology (University). The entire research cycle consisted of several correlated stages. The national and international literature available was analyzed to state objectives and tasks at the first stage. Whole blood stabilization parameters are selected with the concurrent conservation to improve the stability of erythrocyte membranes. The best value of the separation factor is selected wherein the application condition of high separation factor values is taken as the baseline for the blood fractionation. The process of citric acid influence is analyzed as the preservative agent on the blood viscosity, blood $\mathrm{pH}$ and total bacterial content. A calibration dependence graph of the separating unit rotation velocity (separator, centrifuge) is worked out of the unit rotation radius. The fractional composition of the derived protein components of red blood cells of the bovine cattle and porcine bloods is analyzed to prove the benefit of fractionation characteristics obtained. The following fractions are revealed in the packed red cells as follow: haptoglobin, fibrinogen, globulin, one of its three forms, hemoglobin, the protein of the platelet-leukocyte group.
\end{abstract}

Keywords: fractionation, separation factor, blood proteins, packed red cells, heme iron

DOI: $10.21603 / 2500-1418-2016-1-2-70-77$.

\section{INTRODUCTION}

Iron-deficiency anemia is one of the most common human diseases. Pregnant and children aged up to 8 are most susceptible to this disease. As a result, this disease can result in the fertility reduction and an increase in children mortality and serious diseases. To prevent the disease consequences, new therapeutic and preventive products should be investigated and developed to manage the iron deficiency anemia [1].

To date, of all patents relating to iron deficiency anemia management and prevention, only about onefourth are based on the use of heme iron. It is noted also that since 2007, the production of new drugs in this area is lowered. Alimentary albumin is used in many medical products to prevent the iron deficiency that is prepared from the whole blood of slaughter animals, rather than the specially isolated hemoglobin. When such products are absorbed in the body, one is at the risk to absorb the excess amount of allergy-causing components along with nutrient substances, that are mainly leukocytes and modifications thereof to remain in the final product [2-4].

As per the data provided by the Federal Institute for Industrial Property of Russia, about 100 patents only are registered to manage the iron deficiency anemia. Herewith, the majority of patents are valid for over 10 years. More than half of patents relate to developments in food industry, while remaining ones relate to pharmacy, medicine and veterinary sciences. About a quarter of patents focus on researches to manage the iron deficiency anemia using the heme iron, while the rest represent products with various iron complexes in formulation as follow: lactates and sulfates, iron ions, iron oxides and iron sulfate [5].

$20 \%$ patents propose medications to manage the iron deficiency anemia, $80 \%$ patents offer products of therapeutic and preventive effect with the high content of iron in various forms [6]. In addition, such products are additionally saturated with vitamins and mineral nutrients.

Thus, the effective prevention of the iron deficiency anemia requires researches in the field to derive the high quality stock for materials for products rich in digestible iron, that is, as the heme iron.

The blood of slaughter animals is known for relatively rich water activity, the moisture mass fraction and protein. This is to prove its easy degradation in the lack of the adequate conservation and stabilization.

\footnotetext{
Please cite this article in press as: Izgarishev A.V., Karchin K.V., Izgarisheva N.V. Innovation approach to obtain the packed red cells from the slaughter animal blood. Science Evolution, 2016, vol. 1, no. 2, pp. 70-77. doi: 10.21603/2500-1418-2016-1-2-70-77.

Copyright (C) 2016, KemSU. This is an open access article distributed under the terms of the Creative Commons Attribution 4.0 International License (http:// creativecommons.org/licenses/by/4.0/), allowing third parties to copy and redistribute the material in any medium or format and to remix, transform, and build upon the material for any purpose, even commercially, provided the original work is properly cited and states its license. This article is published with open access at http:// science-evolution.ru/
} 
It is therefore urgent to develop a solution that facilitates stabilization (prevent of clotting) with the concurrent conservation $[7,8]$.

The research is aimed to develop stabilizers with the preservative effect that allow extending the shelf life during blood stabilization prior to appropriate processing, as well as the selection of the fractionation characteristics with primary isolation of the heme iron.

\section{OBJECTS AND METHODS OF STUDY}

The following is used as the research item:

- the whole blood of the bovine cattle and pigs obtained as per requirements of SanPiN 2.3.2.1078-01;

- alimentary acetic acid as per GOST 6968-76;

- alimentary citric acid as per GOST 90-2004;

- 5.5 aquatic sodium citrate, dietary, as per GOST 31227-2004;

- drinking water as per GOST 2874-82;

- auxiliary raw stock and materials that meet requirements of the applicable document or those imported (sodium and potassium hydroxide, hydrochloric acid, citric acid, mineral salts) and allowed for use in the food industry.

The mass fraction of iron is determined as per GOST 30648.3-99. To determine the iron content, 1.0-1.2 g of sample is carefully carbonized in the porcelain crucible in the incinerator until red hot. The ash is dissolved in 10 $\mathrm{ml}$ of hydrochloric acid, diluted to $1: 1$, and the resulting solution is evaporated to dryness in the water bath. The dry residue is redissolved in $20 \mathrm{ml}$ of hydrochloric acid (1:1) and placed in the conical flask of $250 \mathrm{ml}$ in volume by rinsing the crucible with $10-15 \mathrm{ml}$ of distilled water. Then, $1.5 \mathrm{~g}$ of potassium iodide is added to the flask, the flask is sealed with a glass stopper and allowed to leave for 5 minutes, and then $70 \mathrm{ml}$ of distilled water is added to titrate with $0.1 \mathrm{~N}$. of sodium thiosulfate solution $(1 \mathrm{ml}$ of $0.1 \mathrm{~N}$. sodium thiosulfate solution corresponds to $5.58 \mathrm{mg}$ of iron). The iron content (\%) is determined by the formula (1),

$$
\mathrm{X}=5.58 \cdot \mathrm{a} \cdot \mathrm{K} \cdot 100 / \mathrm{b},
$$

where a - amount of sodium thiosulfate milliliters consumed to titrate the sample weighed portion; $\mathrm{K}$-correcting factor to $0.1 \mathrm{~N}$. solution of sodium thiosulfate; b-sample weighed portion, in $\mathrm{mg}$.

The stand unit is used to determine the index of the water activity. The indirect method of water activity determination is used by the stand unit that is based on pre-setting of the equilibrium relative air humidity through the working space of the unit. The unit flowchart is shown in Fig. 1.

All the unit elements are interconnected through the silicone hose (5) forming the sealed loop. The fan (4) is designed to create the forced air flow in the sealed loop. The sensors of gauges IT5-TR-2 "Termite" (2) are installed in the outlet and inlet to the working chamber (3). The values of the relative air humidity and temperature measured are shown in the display of IT5-TR-2 "Termite" gauge.

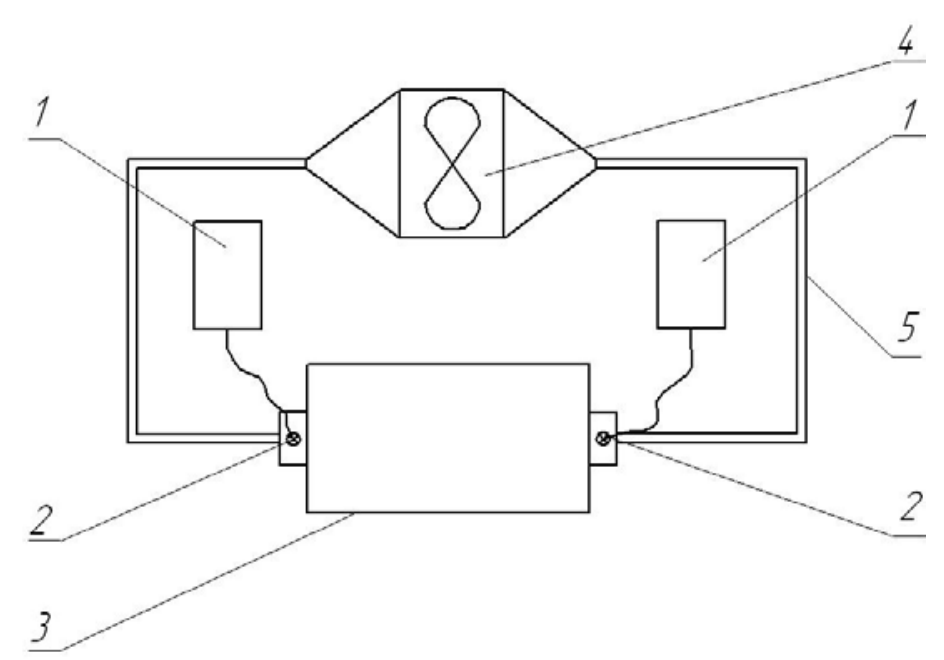

Fig. 1. The flow chart of the stand unit to determine the water activity parameter of food products: $1-$ the IT5-TR-2 "Termite" gauge to measure the relative air humidity and temperature; 2 - sensors of relative air humidity and temperature gauges; 3 - working chamber; 4 - fan; 5 - silicone hose.

The determination of the water activity of food products on the unit consists of two stages: preparatory (draining of the pressure circuit) and primary (setting of equilibrium relative air humidity in the pressure circuit). The volume of water activity $a_{w}$ is found by the formula 2 as follows.

$$
\mathrm{a}_{\mathrm{w}}=\frac{P O B}{100},
$$

where $P O B$ - equilibrium relative air humidity in the pressure circuit, $\%$.
Microbiological parameters are assessed by counting colonies grown in Petri dishes filled with nutrient media. Meat-and-peptone agar, potato and malt agar are used as the culture media. To determine the total contamination of the final product, its aqueous solution is prepared at the ratio of $1: 100,1: 1000$ and $1: 10000$. Each solution prepared is cultured in six Petri dishes. To do so, $0.3 \mathrm{ml}$ of the enzyme solution is taken with the sterile pipette at the burner flame and placed onto the agar surface. Then, the cultured Petri dishes are incubated for $48 \mathrm{~h}$ at $37 \pm 2{ }^{\circ} \mathrm{C}$. 
The content of protein is measured using the total nitrogen (protein) content analyzer "RAPID N ELEMENTAR" that runs by the Dumas' method for sample burning with the total nitrogen content tracing by the thermal conductivity detector. The sample is encapsulated to determine the protein content by the analyzer, wherein the analysis accuracy is $0.5 \%$. The total protein content is calculated by multiplying the total nitrogen in terms of conversion factor for blood proteins that is 6.36 .

The acidity is determined by the activity of hydrogen ions using the potentiometric analyzer. To do so, the test sample is put in the bunsen beaker and an electrode is inserted. The analyzer electrodes do not contact with the beaker walls and bottom. In 10 seconds, the readings are taken as per the instrument scale.

The molecular-mass distribution of proteins and peptides in the resulting hydrolyzates is evaluated by the electrophoretic method in the polyacrylamide gel (PAGE) by the Laemmli method. For this purpose, plates for PAGE polymerization are prepared and the reservoir chambers are filled with the electrode buffer solution (0.066 M Tris, 0.19 M glycine, $0.1 \%$ SDS) for electrophoresis. The previously prepared test sample is put in each well of the gel formed.

The amino acid sequence of the produced peptides is determined using the automated sequencer that runs by the Edman method. This method is based on processing of the test sample with the phenyl isorhodanide resulting in to the abstraction of one amino acid at the $\mathrm{N}$-end of the sequence with its subsequent identification by the liquid chromatography under pressure.

The dry matter content is determined by the refractometer. The sample is pre-diluted with water. The result is multiplied by the dilution coefficient.

\section{RESULTS AND DISCUSSION}

Since blood is the short-life material, its most important parameters are investigated shown in Table 1.
Table 1. Parameters of the stabilized whole blood

\begin{tabular}{|c|c|c|}
\hline \multirow[b]{2}{*}{ Parameter } & \multicolumn{2}{|c|}{ Volume } \\
\hline & $\begin{array}{c}\text { porcine } \\
\text { blood }\end{array}$ & $\begin{array}{c}\text { bovine cattle } \\
\text { blood }\end{array}$ \\
\hline $\begin{array}{l}\text { Mass fraction of } \\
\text { moisture, } \%\end{array}$ & 79.0 & 81.0 \\
\hline Total protein, $\%$ & 22.5 & 17.5 \\
\hline Water activity & 0.99 & 0.99 \\
\hline $\mathrm{pH}$ & 7.85 & 7.55 \\
\hline Hemoglobin, \% & 14.5 & 10.5 \\
\hline $\begin{array}{l}\text { Viscosity relative to } \\
\text { water viscosity }\end{array}$ & 4.3 & 4.2 \\
\hline
\end{tabular}

When developing the stabilizer formulation, the works are based on the principle used to preserve the human blood. It uses $4 \%$ sodium citrate solution or $0.75 \%$ solution of trisodium phosphate. Also, the citric acid is added that favorably affects the native red blood cells and create conditions unfavorable for the microbial growth. The trisodium phosphate solution has a strong waterbinding power to affect the blood, thereby adding to its preservation.

As the basis of the porcine and bovine cattle blood stabilizer to develop, $4 \%$ sodium citrate solution is used and $10 \%$ citric acid solution is used as most appropriate preserving agent with the proportioned concentration to add to the basic stabilizer solution.

In order to control the impact of the citric acid in the stabilized blood on the red blood cell membrane, the concentration of the acid to be added to the main solution is controlled as per the blood $\mathrm{pH}$ upon stabilization. Analysis of the impact caused by the concentration of the the citric acid added to the stabilizer on the blood $\mathrm{pH}$ is shown in Fig. 2.

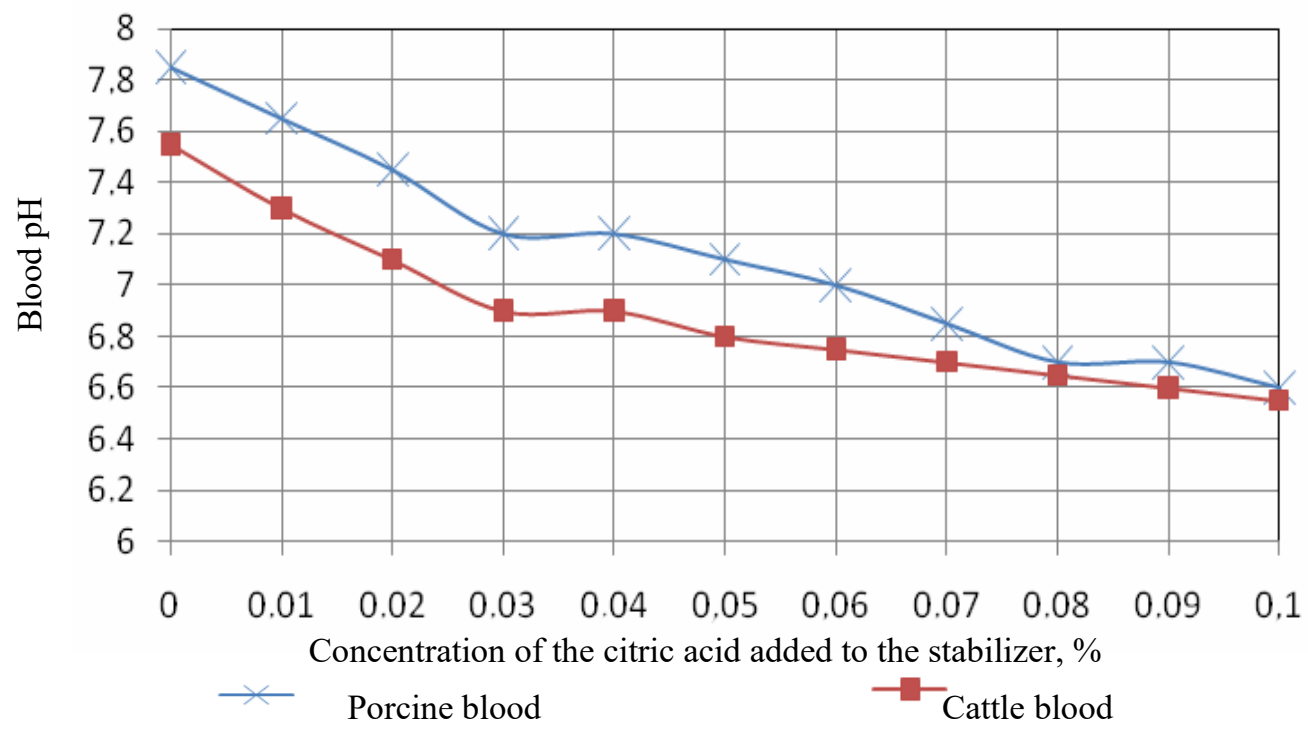

Fig. 2. Dependence of the blood $\mathrm{pH}$ on the concentration of the citric acid added to the stabilizer. 
When adding the stabilizer with the citric acid to the blood, the blood $\mathrm{pH}$ reduction is reported in the porcine and bovine cattle blood to prove the acidity increase.

It should be also taken into account that an increase in the citric acid concentration causes an increase in the blood viscosity, either. The blood viscosity is mainly produced by erythrocyte proteins and plasma proteins to a lesser extent. The blood viscosity is determined in relation to the water viscosity, whereby the standard value corresponds to $4.5 \div 5.0$. The plasma viscosity does not exceed $1.8 \div 2.2$. Thus, of the blood plasma proteins, prothrombin and fibrinogen show the greatest influence on the viscosity volume which present in the blood prior to the fractionation process. Fig. 3 shows the dynamics of the viscosity change in the stabilized whole blood caused by the concentration of citric acid.

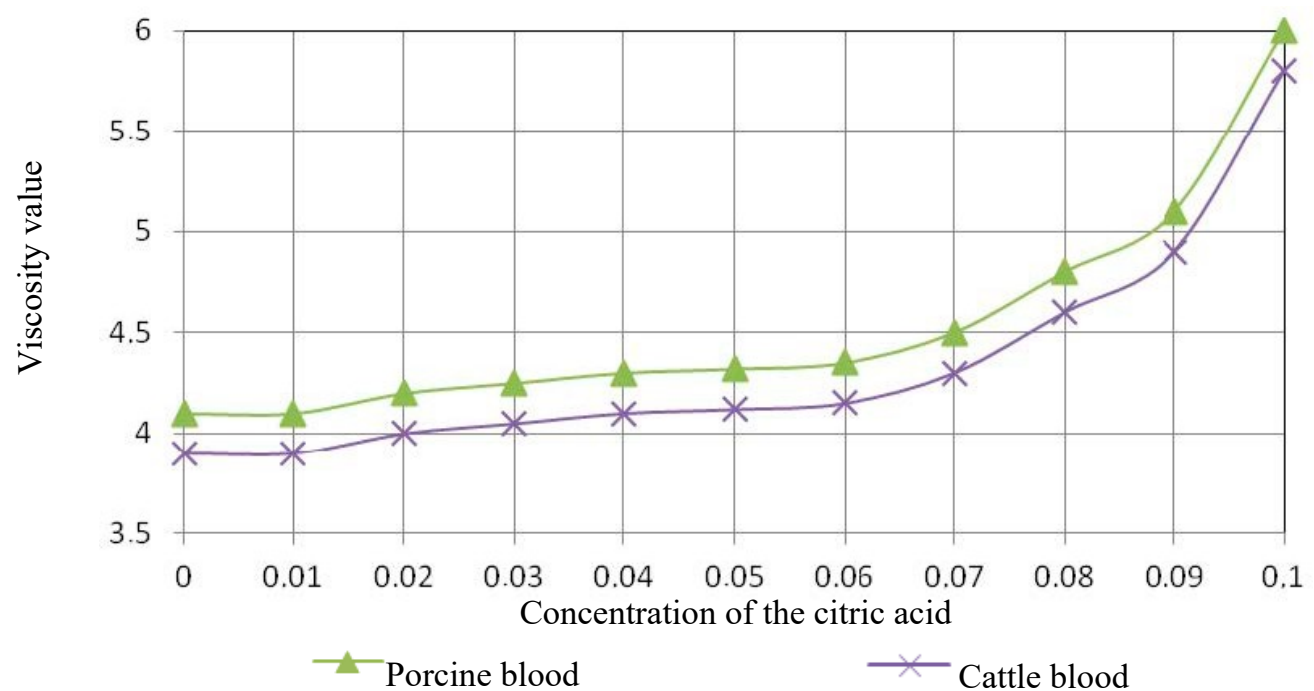

Fig. 3. Dynamics of the viscosity change of the stabilized whole blood caused by the concentration of citric acid.

Data presented in Fig. 2 show that adding the citric acid at the concentration of $0 \div 0.06 \%$ to the stabilized whole blood, its viscosity slightly increases; for the porcine blood, the viscosity is at $4.10 \div 4.35$, and for the bovine cattle blood, it is within $3.90 \div 4$. 15 . In this case, the most stable values are reported with the citric acid concentration of $0.03 \div 0.04 \%$. An increase of the acid concentration results in the change of the slope of curve and at the concentration of $0.1 \%$, the viscosity value for the porcine blood is 6.0 and 5.8 for the bovine cattle blood, which is not desirable since the blood transportation is projected through pipelines prior to its fractionation.

Thus, based on the data obtained for the change in viscosity and blood $\mathrm{pH}$ due to the concentration of citric acid added to the primary stabilizer solution, $10 \%$ citric acid solution of $0.035 \%$ concentration is advisable to use as the additional preserving agent.

Blood is the good nutrient medium for microorganisms. Their vital activity may result in accumulation of protein degradation products in blood. The accumulation of degradation products may give the hemolysis effect, that will cause the destruction of red blood cells and as a consequence, loss of iron. In such conditions, the hemolyzed blood is black. Microbiological studies are performed to understand the action of microorganisms and the effect of additional conservation. They are shown in Fig. 4.

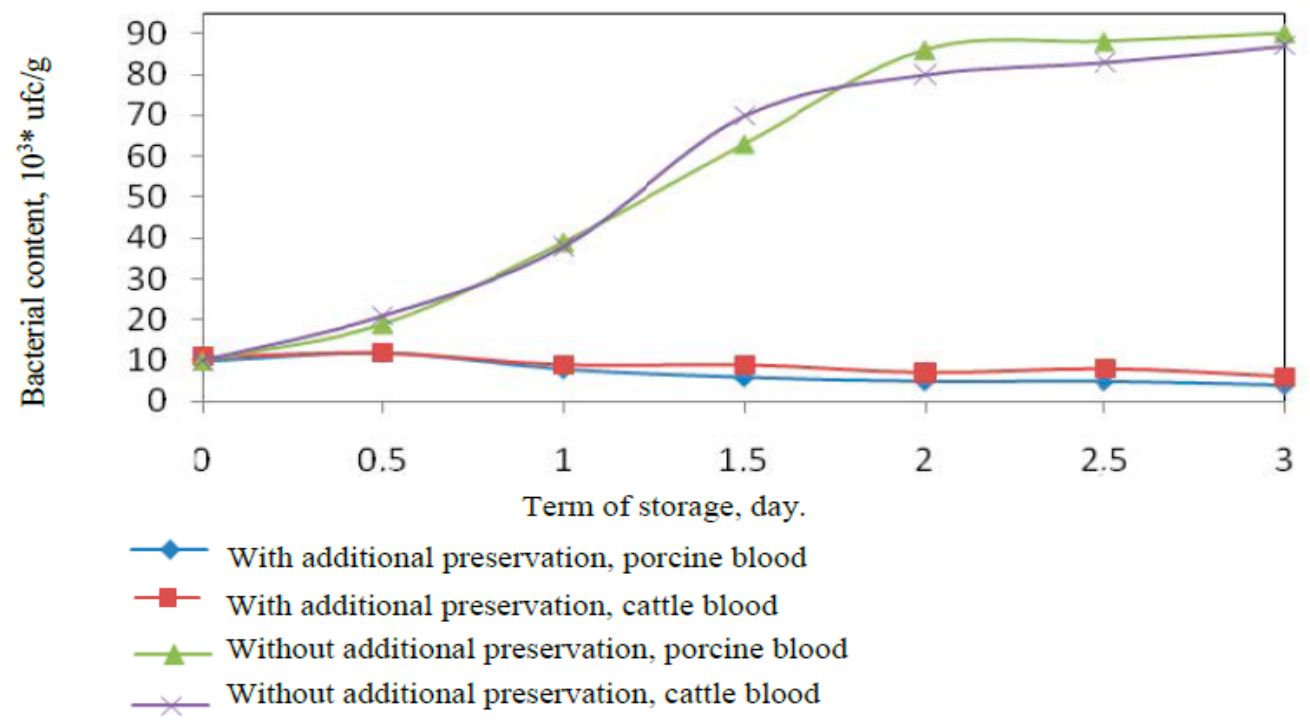

Fig. 4. Dynamics of bacterial growth during storage for the whole stabilized blood with and without additional preservation. 
Based on the data in Fig. 4, it is possible to state the beneficial effects of additional preservation at stabilization.

The main criterion to select the fractionation parameters is the condition to prevent the red blood cells hemolysis prior to hydrolysis. Premature hemolysis is not preferable since it facilitates penetration of hemoglobin molecules to the blood plasma, and, accordingly, it reduces the total hemoglobin count in the red blood cell mass, hence, resulting in non-standard losses. When separating the blood for plasma and red blood cells, the principle of centrifugal acceleration is applied that results in separation of heavier elements (erythrocytes) under the impact. It is therefore the separation factor $(\mathrm{Fr})$ has been selected as the prevailing parameter. And we specifically aimed to achieve the effective separation at the maximum possible low separation factor value. Apart from the selection of the best separation factor, we planned to select the best characteristics for the red blood cells isolation as follow: process length and temperature. These principles are put to the core of the investigation stage to evaluate the dependence on the residual iron in blood plasma upon fractionation on the separation factor as shown in Fig. 5.

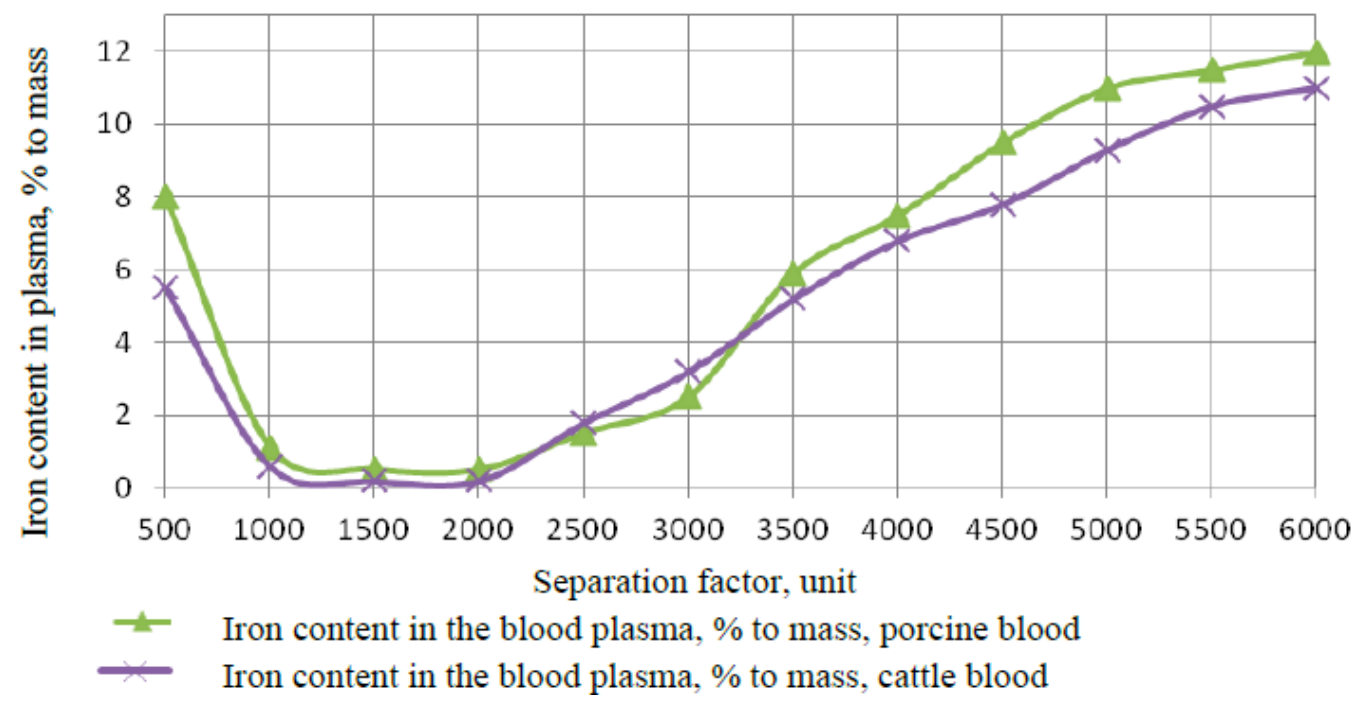

Fig. 5. Dynamic pattern of the residual iron content due to the separation factor applied.

The residual iron content in the blood plasma, as described above, with the separation factor value of less than 1000 units is at the fairly high level, as evidenced by its amount from 1.1 to $8.0 \mathrm{mg} \%$ when separating the porcine blood, and from 0.6 to $5.5 \mathrm{mg} \%$ when separating the bovine cattle blood. The blood fractionation at higher separation factor values results in the initial decrease in the residual amount of plasma iron $(1500 \div 2000$ units) and then in the relatively consistent increase that proves the phenomenon of red blood cells destruction when exposed to higher centrifugal acceleration values. It should be also noted that the least residual amount of red blood cells in the plasma is at the level of $0.5 \mathrm{mg} \%$ for the porcine blood and $0.2 \mathrm{mg} \%$ for the bovine cattle blood and the separation factor value, thus, makes 2000 units.

Further studies are conducted to assess the dependence of the fractionation process on different separation factor values. The studies are shown in the Fig. 6.

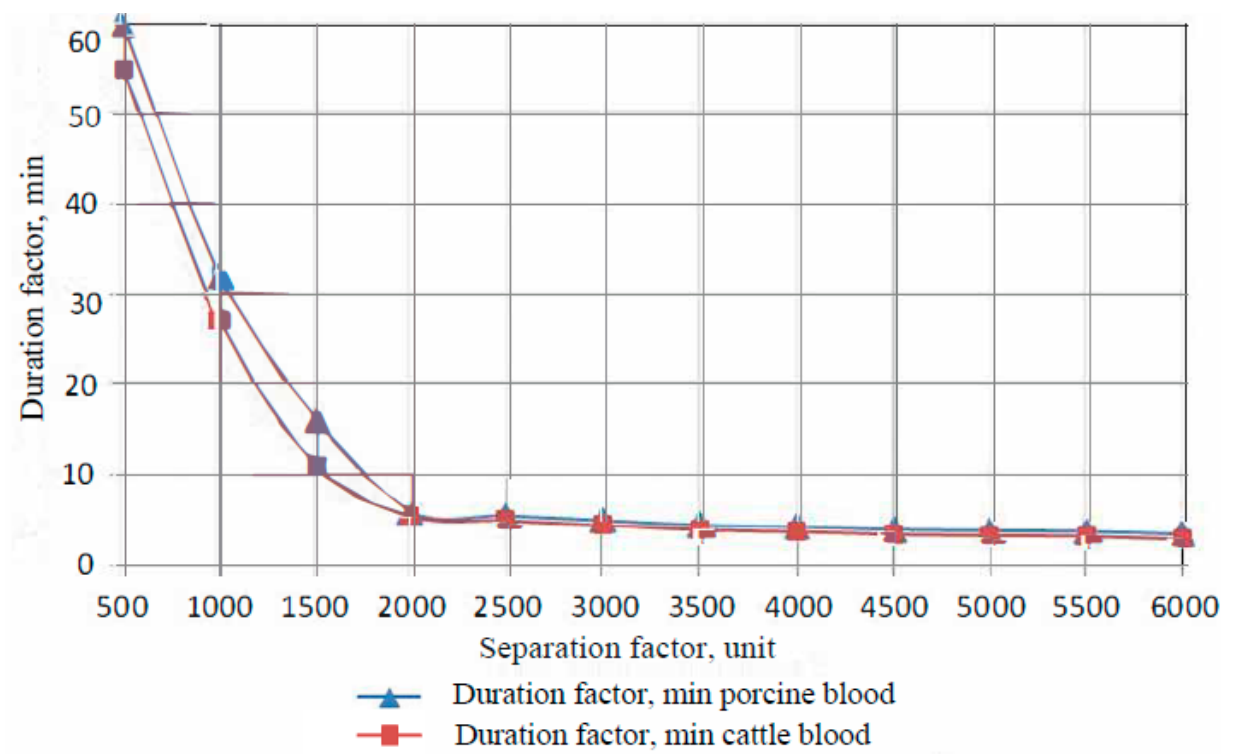

Fig. 6. Dynamic pattern of the separation factor impact on the process length. 
It is seen from the Fig. 5 that the maximum process length for the porcine blood is 60 minutes, and is consistent with the minimum value of the separation factor equal to 500 units. The process length is 55 minutes at the same separation factor for the bovine cattle blood. When reaching the separation factor 2000 units, the length of process for the porcine blood reduces to 6 minutes and to 5.5 minutes for the bovine cattle blood. When the separation factor value is $2000 \div 6000$ units, the processing time slightly decreases that roughly corresponds to the drop from 6 to 3.5 minutes for the porcine blood and from 5.5 minutes to 3.0 minutes - for the bovine cattle blood.
Thus, based on the data obtained for the process length, as well as the zero factor of premature hemolysis and the minimum amount of residual iron in plasma upon fractionation, 2000 units should be taken as the best value for the separation factor.

It should be also taken into consideration that during the primary processing, the blood temperature is close to that of the animal, though the fractionation results in some iron losses associated with the red blood cell hemolysis. To avoid unwanted loss of iron, the temperature at which the minimal losses occur should be calculated. To do so, studies are conducted to evaluate the dependence of the residual iron on the process temperature, shown in the Fig. 7.

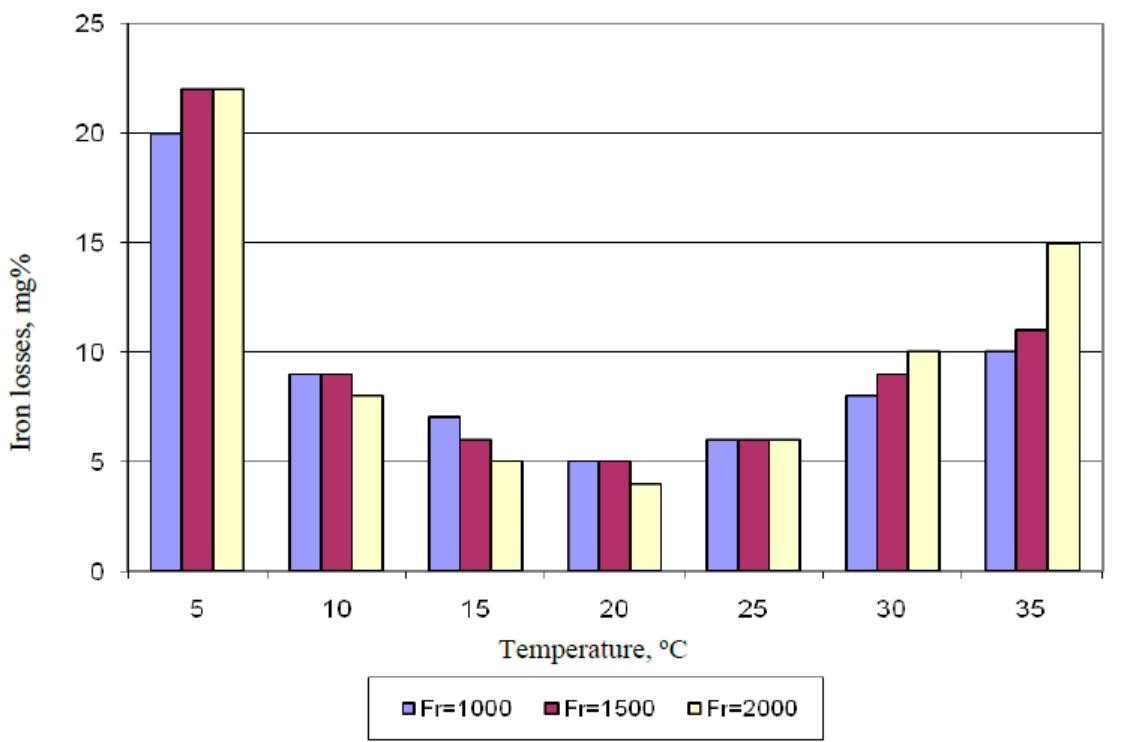

Fig. 7. Dependence of the residual iron on the process temperature.

The data in Fig. 7 show that the best result is reported at the process temperature equal to $20^{\circ} \mathrm{C}$, whereas the least losses are seen at the 2000 units of separation factor.

Hence, we may conclude on the following. The approach that we applied suggests higher rotational speed of fractionation with no significant losses of red blood cells, which is very important. The separation factor value should not exceed 2000 units. Such values is efficient to quickly fractionate the blood. The use of the same separation factor value for the blood of the bovine cattle and pig, due to initial difference in physical properties of their blood, allows to expose the animal blood for different time period, that is 5.5 minutes for the bovine cattle blood and 6 minutes - for the porcine blood.

Parameters to obtain the packed red cells from the bovine cattle and porcine blood have almost the analogous values for the blood of both animal groups. When isolating erythrocytes from blood, the stabilization process should be prioritized that, in this case, followed by the use of additional preservative agent.

Table 2. Parameters to obtain the packed red cells from the whole blood of pigs and bovine cattle

\begin{tabular}{|l|c|c|c|}
\hline $\begin{array}{l}\text { Type of raw } \\
\text { material }\end{array}$ & Stabilizer components & Separation length, min & $\begin{array}{c}\text { Value of separation } \\
\text { factor, units }\end{array}$ \\
\hline Porcine blood & $4 \%$ solution of sodium citrate $+0.035 \%$ solution of \\
citric acid & 6.0 & 2000 \\
\cline { 1 - 3 } $\begin{array}{l}\text { Bovine cattle } \\
\text { blood }\end{array}$ & 5.5 & 2000 \\
\hline
\end{tabular}

Parameters to isolate red blood cells from the blood obtained allow higher rotational speed during fractionation with no significant RBC losses, which is essential for our work. To simplify the principle of developed fractionation parameters in practice, we calculate the relation of the applied rotation speed to the fractionation device (separator, centrifuge) to the radius of rotation of the said device. The calibration curve is shown in Fig. 8.

This curve allows the quick selection of fractionation parameters in view of specification of the separator and in line with the separation conditions selected (separation factor value should not exceed $\mathrm{Fr}=2000)$. 


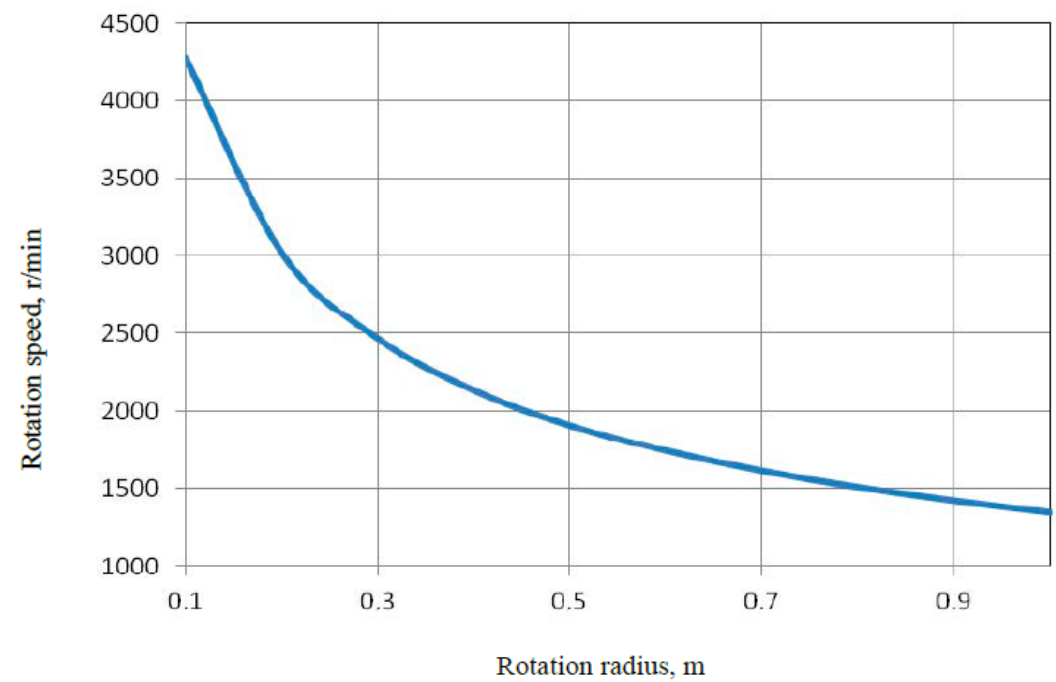

Fig. 8. Calibration curve of the dependence of the separating device velocity (separator, centrifuge) on its rotation radius.

In perspective, we plan to obtain the protein hydrolyzate from the isolated $\mathrm{RBC}$ enriched with the heme iron. It is therefore necessary to understand physical and chemical composition and properties of the raw stock for proposed hydrolysis. Therefore, the study are conducted to evaluate the fractional composition of the obtained RBC protein components of the bovine cattle and porcine bloods. The data is shown in Fig. 9 and Table 3. The Fig. shows the electrophoresis data, and the actual values and the description of isolated fractions of the electrophoretic analysis are tabulated.

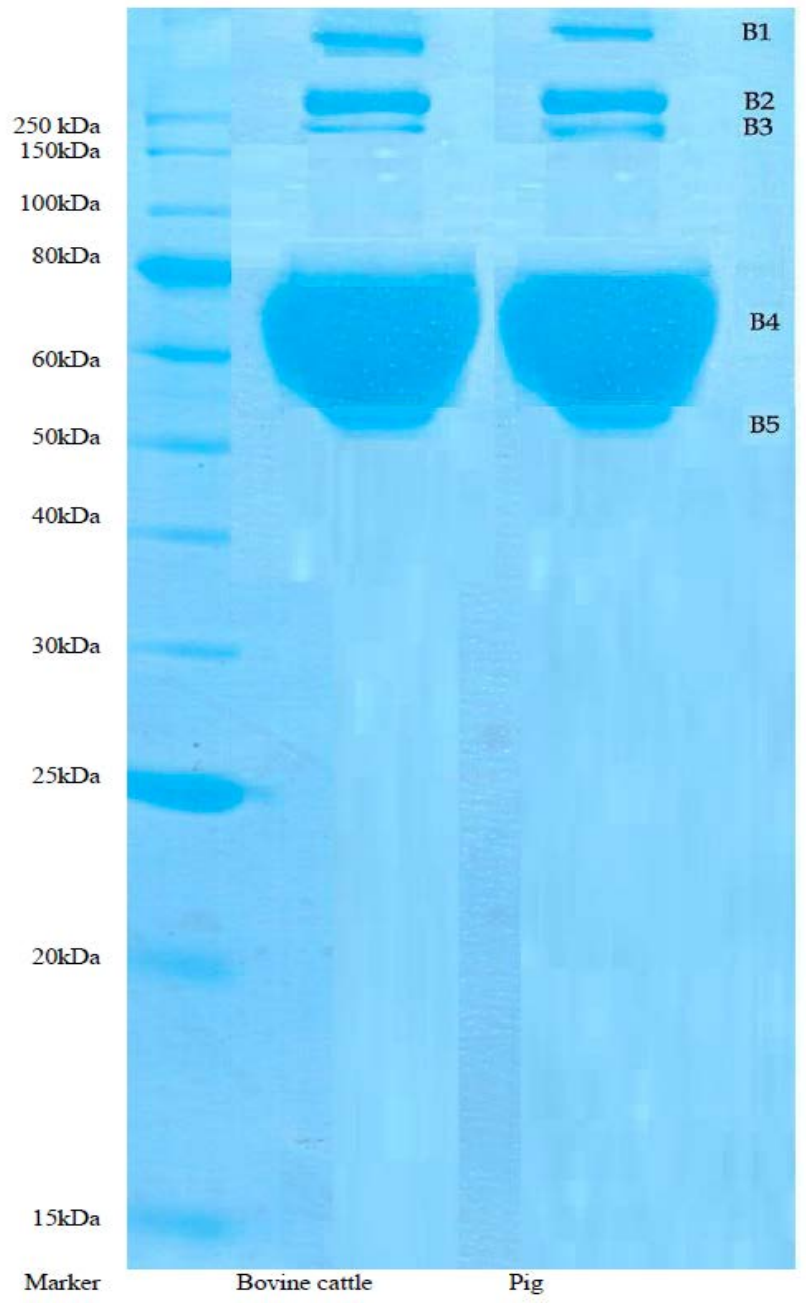

Fig. 9. Polyacrylamide gel electrophoresis data. 
Table 3. Actual values and description of electrophoretic analysis fractions obtained

\begin{tabular}{|c|c|c|c|c|}
\hline \multirow{2}{*}{$\begin{array}{c}\text { Band } \\
\text { number }\end{array}$} & \multirow{2}{*}{ Molecular mass, $\mathrm{kDa}$} & \multicolumn{2}{|c|}{$\%$, of the total protein content } & \multirow{2}{*}{ Fraction } \\
\cline { 3 - 4 } & & Porcine blood RBC & Bovine cattle RBC & Haptoglobin \\
\hline B1 & 854.23 & 1.98 & 4.50 & Fibrinogen \\
\hline B2 & 311.80 & 4.96 & 4.90 & Globulin, one of 3 forms \\
\hline B3 & 208.93 & 2.10 & 1.90 & Hemoglobin \\
\hline B4 & 66.50 & 88.76 & 86.50 & Leucocyte and platelet group protein \\
\hline B5 & 52.54 & 2.20 & 2.20 & \\
\hline
\end{tabular}

The results of fractional study of obtained $\mathrm{RBC}$ protein components in the bovine cattle and porcine bloods prove the benefit of fractionation parameters obtained. RBC fractions of both bovine cattle and porcine blood have the highest values for the hemoglobin protein: molecular mass of $66.50 \mathrm{kDa}$, $88.76 \%$ of the total content for the porcine blood RBC and $86.50 \%$ for the bovine cattle blood RBC. Protein fractions are reported in all fractions with no heme iron in composition. This is the haptoglobin protein with the molecular mass of $854.23 \mathrm{kDa}$, the quantitative content of $1.98 \%$ for the porcine blood RBC and $4.50 \%$ for the bovine cattle blood RBC. Fibrinogen protein is also reported with the molecular mass of $311.80 \mathrm{kDa}$ and the quantitative content of $4.96 \%$ for the porcine blood RBC and $4.90 \%$ for the bovine cattle blood RBC.

One of three forms of globulin available in isolated fractions with the molecular mass of $208.93 \mathrm{kDa}$, the quantitative content of $2.10 \%$ for the porcine blood RBC and $1.90 \%$ for the bovine cattle blood, accordingly. The protein fraction is also reported that may be referred to the leucocyte and platelet group of proteins with the molecular mass of $52.54 \mathrm{kDa}$, the quantitive content of $2.20 \%$ for the porcine and bovine cattle blood RBC.

\section{REFERENCES}

1. Kocherga O.I. Gematogen [Haematogen]. Patent RF, no. 2179227, 2002.

2. Rogov I.A., Zabashta A.G., Kazyulin G.P. Obshchaya tekhnologia myasa i myasoproduktov [General meat and meat product technology]. Moscow: KolosS Publ., 2000. 367 p.

3. Fayvishevskiy M.L. Netraditsionnye tekhnologii pererabotki i ispolzovaniya pishchevoy krovi uboinykh zhyvotnykh [Nonstandard technologies to process and use the slaughter animal blood]. Vsyo o myase [All about meat], 2006, no. 1, pp. 14-17.

4. Salavatulina R. Ratsional'noe ispol'zovanie syry'a v kolbasnom proizvodstve [Rational use of stock in sausage production]. SPb.: GIORD Publ, 2005. 248 p.

5. Kudasheva G.B., Khakimova F.Z., Israfilov A.G., Lyutov A.G., Enikeeva S.A. Sposob polucheniya al'bumina [Albumin production method]. Patent RF, no. 2140287, 1999.

6. Kriger O.V. Advantages of Porcine Blood Plasma as a Component of Functional Drink. Food and Raw Materials, 2014, no. 2, pp. 26-32. doi: 10.12737/5456.

7. Clara S.F. Bah, Bekhit A., Carne A., McConnell M.A. Slaughterhouse Blood: An Emerging Source of Bioactive Compounds Comprehensive Reviews in Food Science and Food Safety, 2013, vol. 12, pp. 314-331. doi: 10.1111/1541-4337.12013.

8. Lafarga T., Wilm M., Wynne K., Hayes M. Bioactive hydrolysates from bovine blood globulins: Generation, characterisation, and in silico prediction of toxicity and allergenicity. Journal of Functional Foods, 2016, vol. 64, no. 8, pp 1741-1750. doi: 10.1021/acs.jafc.5b06078.

\section{Alexandr V. Izgarishev}

Cand.Sci.(Eng.), Scientific Researcher of Scientific - Educational Center, Kemerovo Institute of Food Science and Technology (University), Kemerovo, Russian Federation

\section{Konstantin V. Karchin}

Cand.Sci.(Eng.), Assistant of the Bionanotechnology Department, Kemerovo Institute of Food Science and Technology (University), Kemerovo, Russian Federation

\section{Natalia V. Izgarisheva}

Cand.Sci.(Eng.), Assistant of the Bionanotechnology Department, Kemerovo Institute of Food Science and Technology (University), Kemerovo, Russian Federation 